\title{
Resting Stage and Newly Hatched Hydroid of a Cool Water Hydrozoan Species Climacocodon ikarii Uchida (Hydrozoa, Margelopsidae)
}

$\operatorname{AUTHOR}(S)$ :

Kubota, Shin

CITATION:

Kubota, Shin. Resting Stage and Newly Hatched Hydroid of a Cool Water Hydrozoan Species Climacocodon ikarii Uchida (Hydrozoa, Margelopsidae). PUBLICATIONS OF THE SETO MARINE BIOLOGICAL LABORATORY 1993, 36(1-2): 85-87

\section{ISSUE DATE:}

1993-03-30

URL:

http://hdl.handle.net/2433/176220

RIGHT: 


\title{
Resting Stage and Newly Hatched Hydroid of a Cool Water Hydrozoan Species Climacocodon ikarii Uchida (Hydrozoa, Margelopsidae)
}

\author{
Shin Kubota \\ Seto Marine Biological Laboratory, Kyoto University, \\ Shirahama, Wakayama 649-22, Japan
}

With Text-figure 1

\begin{abstract}
A resting stage was found in a cool water hydrozoan, Climacocodon ikarii, the development of which had been thought to be tachygenetic. The resting stage in the form of a cyst, and the newly hatched hydroid, are described.
\end{abstract}

Key words: resting stage, cyst, newly hatched hydroid, cool water bydrozoan, Ciimacocodon ikarii

\section{Introduction}

Among the anthomedusae, Climacocodon ikarii Uchida, 1924 is unique in having a pelagic, solitary hydroid (Uchida, 1924). The life cycle of this species was clarified by laboratory-rearing (Kubota, 1979) and the tachygenesis pointed out by Uchida (1924) was demonstrated, i.e. an actinula-like hydroid develops directly on the manubrium of the female medusa and the liberated hydroid soon produces medusa buds. However, a resting stage was discovered by culture of this species collected from two localities in northern Japan and the primary hydroid was obtained after a period of dormancy in the form of a cyst. The resting cyst and newly hatched hydroid stages are described and the life cycle of the cool water hydrozoan Climacocodon ikarii is illustrated in this paper.

\section{Materials and Methods}

Mature female and male medusae were collected in Hokkaido, northern Japan, from Oshoro in late January, 1988, and from Muroran in early May, 1988. They were reared in small polystyrene vessels $(60 \mathrm{~mm}$ wide and $30 \mathrm{~mm}$ deep or $80 \mathrm{~mm}$ wide and $40 \mathrm{~mm}$ deep) filled with artificial sea water, mostly at $6^{\circ} \mathrm{C}$ and partly at $12^{\circ} \mathrm{C}$. Crossing was carried out between these stocks immediately after collection and eggs were spawned within several days. Eggs became cysts, secreting a thin periderm on the bottom of the rearing vessel in each population within two weeks after crossing. The culture medium was frequently changed and subsequent development of the embryo was observed. Newly hatched hydroids began to appear on the bottom of the container three months after encystment at $6^{\circ} \mathrm{C}$, two months after at $12^{\circ} \mathrm{C}$, leaving the empty sheaths of the cysts, the outlines of which still remained clear.

All measurements were taken from living specimens except for some cysts which were empty due to hatching of the hydroid, and ranges are shown together with mean $\pm S D$ and sample size in parentheses.

Publ. Seto Mar. Biol. Lab., 36(1/2), 85-87, 1993. (Article 5) 


\section{Description of cyst and newly hatched hydroid}

The cysts have a thin, chitinous sheath, a plano-convex shape, and a milky white color, and they measure $0.22-0.28 \mathrm{~mm}(0.24 \pm 0.02 \mathrm{~mm}, \mathrm{~N}=7)$ in diameter. One other cyst which was on top of another cyst was smaller, $0.18 \mathrm{~mm}$ in diameter.

The newly hatched hydroids are actinula-like in shape, and are $0.31-0.52 \mathrm{~mm}$ long $(0.37 \pm 0.06 \mathrm{~mm}, \mathrm{~N}=11)$ and $0.20-0.25 \mathrm{~mm}(0.24 \pm 0.02 \mathrm{~mm}, \mathrm{~N}=11)$ in $\max -$ imum width. The aboral tentacles are always more numerous and longer than the oral tentacles. There are 13-19 $(15 \pm 2, \mathrm{~N}=11)$ aboral tentacles arranged in two whorls and 5-7 $(6 \pm 1, N=11)$ oral tentacles in a circlet. Both kinds of tenta-
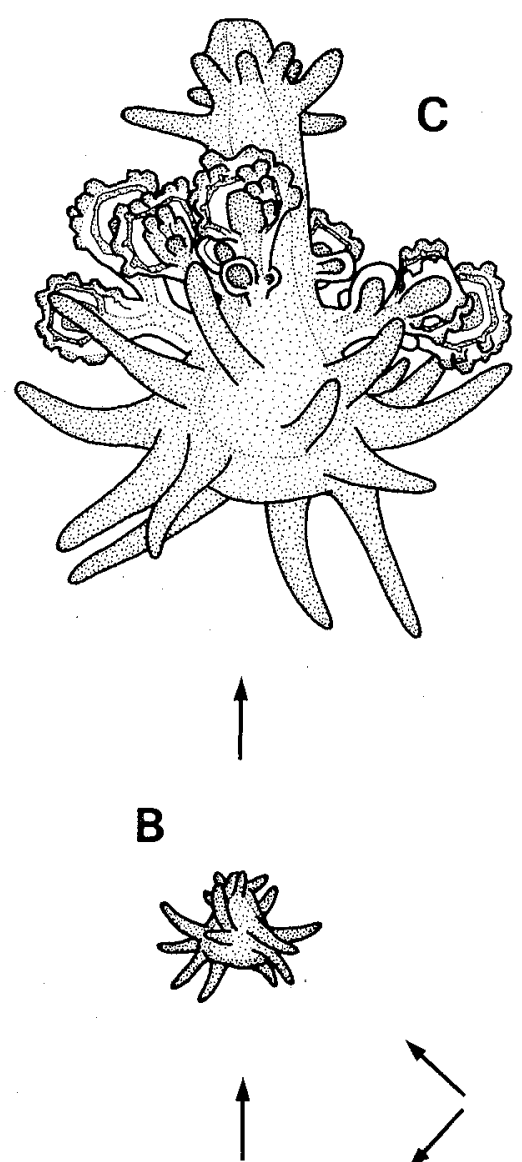

A

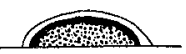

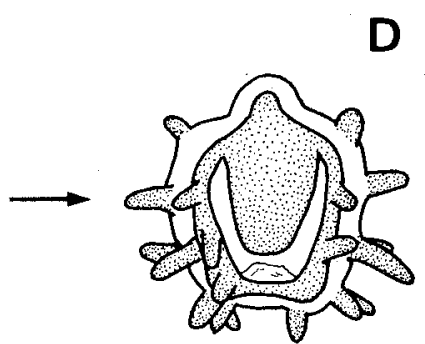

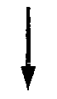

$\mathbf{E}$

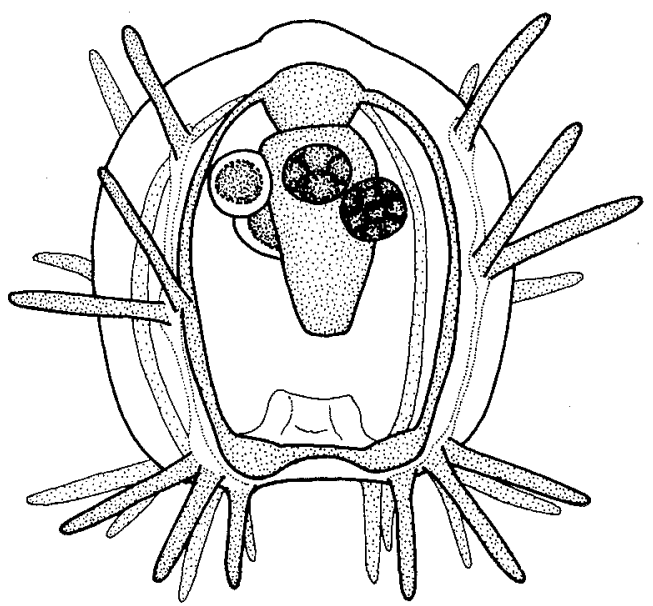

Fig. 1. Life history of Climacocodon ikarii. A: cyst. B: primary hydroid. C: well-developed hydroid with many medusa buds. D: newly liberated medusa. E: female mature medusa with cleaving eggs. B-E: redrawn from Kubota, 1979. 
cles are filiform, and the aboral ones are up to $0.20 \mathrm{~mm}$ long and the oral ones up to $0.08 \mathrm{~mm}$ long.

Remarks. The present newly hatched hydroid is similar to the actinula-like hydroid that developed directly on the manubrium of a female medusa as described by Kubota (1979). Now the resting stage is known, and it is confirmed that the life history of Climacocodon ikarii (Fig. 1) is similar to that of Margelopsis haeckeri Hartlaub described by Werner (1955), though the latter develops parthenogenetically. Both the hydroid and medusa (female and male) of $C$. ikarii appeared only in the cold season in Japan (see Kubota, 1979), and this species may pass the remainder of the year in the form of cysts. C. ikarii is the third species so far known to form a dormant cyst in Japan besides Hataia parva and Fukaurahydra anthoformis. This is also another example of the prevalence of cyst formation in solitary hydroids living in cool or cold waters (see Yamada \& Kubota, 1991).

\section{References}

Kubota, S. 1979. Morphological notes on the polyp and medusa of Climacocodon ikarii Uchida (Hydrozoa, Margelopsidae) in Hokkaido. J. Fac. Sci. Hokkaido Univ. Ser. VI, Zool., 22(1): 122 136.

Uchida, T. 1924. On a new "pelagic" hydroid Climacocodon ikarii n. gen., n. sp. Jap. J. Zool. 1: 5965.

Werner, B. 1955. Über die Fortpflanzung der Anthomeduse Margelopsis haeckeri Hartlaub durch Subitan- und Dauereier und die Abhängigkeit ihrer Bildung von äußeren Faktoren. Verh. D. Zool. Ges. Tübingen: 124-133.

Yamada, M. \& S. Kubota. 1991. Notes on the morphology, ecology and life cycles of Fukaurahydra anthoformis and Hataia parva (Hydrozoa, Athecata). Hydrobiologia 216/217: 159-164. 